\title{
ELECTRONIC NETWORKING TECHNOLOGIES, INNOVATION MISFIT AND PLANT PERFORMANCE
}

\author{
by \\ Robert G. Fichman * \\ Boston College - Wallace E. Carroll School of Management \\ and \\ Nigel P. Melville * \\ University of Michigan
}

CES 10-03

February, 2010

The research program of the Center for Economic Studies (CES) produces a wide range of economic analyses to improve the statistical programs of the U.S. Census Bureau. Many of these analyses take the form of CES research papers. The papers have not undergone the review accorded Census Bureau publications and no endorsement should be inferred. Any opinions and conclusions expressed herein are those of the author(s) and do not necessarily represent the views of the U.S. Census Bureau. All results have been reviewed to ensure that no confidential information is disclosed. Republication in whole or part must be cleared with the authors.

To obtain information about the series, see www.ces.census.gov or contact Cheryl Grim, Editor, Discussion Papers, U.S. Census Bureau, Center for Economic Studies 2K130B, 4600 Silver Hill Road, Washington, DC 20233, CES.Papers.List@census.gov. 


\begin{abstract}
Prior work on information technology (IT) adoption and economic impacts typically employs an instrumental logic in which firms lead with innovation when they possess characteristics that make it economically beneficial to do so and lag when they do not. However, firms may deviate from this idealized picture when they possess characteristics of an innovation laggard but exhibit the behavior of an innovation leader (or vice versa), with implications for the returns to IT investment. This study develops a conceptual framework and hypotheses regarding the implications of such deviations, which we call innovation misfits. Using a data set comprising measures of the adoption of electronic networking technologies (ENT) in over 25,000 U.S. manufacturing plants, productivity regression estimation reveals a consistent pattern that the association between IT and productivity is diminished in the presence of innovation misfit. We discuss the implications of innovation misfit for scholarship and management practice, which are numerous.
\end{abstract}

* The research in this paper was conducted while the authors were Special Sworn Status researchers of the U.S. Census Bureau at the Michigan Research Data Center. Any opinions and conclusions expressed herein are those of the authors and do not necessarily represent the views of the U.S. Census Bureau. All results have been reviewed to ensure that no confidential information is disclosed. Support for this research at the Michigan RDC from NSF (ITR0427889) is also gratefully acknowledged. We thank Ron Ramirez, Vern Richardson, Vijay Gurbaxani, and Kenneth L. Kraemer for valuable comments and suggestions. The paper has also benefited from suggestions from seminar participants at the Carnegie Mellon University, University of Hawaii, the University of California, Irvine, University of Notre Dame, University of Pittsburgh, University of South Florida, and the University of Western Ontario. We also thank Maggie Levenstein, Stan Sedo, and Clint Carter at the Michigan Census Research Data Center for helpful guidance and critical administrative and data support. Financial support for this research at the Michigan Census Research Data Center is gratefully acknowledged. All remaining errors are ours. 


\section{Introduction}

A large literature has examined the antecedents of organizational adoption of information technology (IT) (Fichman 2000; Swanson 1994). The typical goal of these studies has been to identify a set of characteristics that distinguish leading adopters from laggards in some context (Fichman 2004b), resulting in a profile of an innovator (and its mirror image, the profile of a laggard). The innovator profile is of interest because it can help technology vendors and proponents better target their marketing efforts. It also provides prospective adopters with a yardstick of sorts to see whether they measure up as a typical candidate for early adoption.

The majority of this research is based on an instrumental logic in which firms are expected to take the lead with adoption when they possess characteristics that make it economically beneficial to do so, and to hold back when they do not. In effect, these studies assume managers engage in a predominantly mindful process (Swanson and Ramiller 2004) of sizing up whether adoption makes sense given their particular situation, based on such questions as: Is the innovation compatible with our existing technologies, strategies and practices? Do we have the resources (e.g., money, expertise, managerial support) necessary to adopt? Are we structurally and culturally well positioned to adopt? Is our competitive environment one that would especially reward being a leader - or punish being a laggard? Organizations that can answer such questions in the affirmative have the profile of an innovation leader, while those that cannot have the profile of an innovation laggard.

Despite its prevalence in the literature, the idealized view of the mindfully adopting firm may not fully represent reality. For example, mimetic isomorphism was an important factor in KMart's decision to adopt new information technologies to better compete with Wal-Mart - however, by copying what was explicit (technologies) but not copying what was tacit (changes to business processes, structures, and work practices) KMart’s \$130 million IT investment was ultimately written off (Nelson 2007). More generally, when a firm is not mindful in its IT investment decisions we propose that the result is likely to be an innovation misfit: a gap between a firm’s expected level of innovation (based on 
its profile as a leader or a laggard) and its actual innovation behaviors (e.g., early vs. late adoptions). Innovation misfit is one possible explanation for the substantial rate of IT innovation failure documented in the literature (Avison et al. 2006; Nelson 2007).

Intuitively, we would expect that, on average, firms that have the normative profile of laggards but adopt like leaders would be less prone to innovate successfully and should have fewer opportunities to exploit the fruits of innovation should they manage to assimilate the technology against the odds. Conversely, firms that have the profile of a leader but act like laggards should experience an opportunity cost for missing out on a (presumably) beneficial technology that similarly positioned competitors are exploiting. Prior research has employed analogous logic to other contexts, such as the impact of the match between activity-based costing and manufacturing characteristics on plant performance (Ittner 2002). However, we are unaware of any research using this approach to examine IT innovation adoption, which brings us to our primary research question: What is the impact of IT innovation misfit on the association between information technology and organizational performance?

The structure of the paper is as follows. In Section 2 we develop the concepts of overadoption misfit and under-adoption misfit, theorize about the impact of each type of misfit on organizational performance, and consider explanations for why pervasive misfits might be observed in practice. In Section 3 we develop a conceptual model for IT innovation misfit and develop a set of hypotheses relating innovation misfit to the association between IT innovation and organizational performance. In Section 4 we explain our research methodology, including: description of a unique dataset of electronic networking technology (ENT) adoption in over 25,000 manufacturing plants, development of econometric models, operationalization of constructs, and presentation of descriptive statistics. In Section 5 we present our empirical findings, including baseline estimations and robustness and sensitivity analyses. Results of a two-stage estimation procedure including a Poisson count model and instrumental variables controlling for endogeneity provide a strong pattern of support for our primary hypothesis that innovation misfit negatively moderates the relationship between ENT adoption and labor productivity. Specifically, we find that over-adoption reduces the 
impact of ENT on labor productivity by about one half, while under adoption reduces it by about two thirds. In Section 6 we consider possible explanations for these findings and wrap-up with a discussion of the implications of our work for research and practice. We provide concluding remarks in Section 7.

In summary, the main contributions of this work are: (1) development of the IT innovation misfit concept; (2) development of theory-based hypotheses positing negative implications for the impact of IT innovation misfit on the association between IT innovation and organizational performance; and (3) quantitative analysis yielding empirical support for the IT innovation misfit thesis in the context of electronic networking technologies in U.S. manufacturing plants.

\section{Prior Research}

\subsection{The Dominant Instrumental Logic of Information Systems (IS) Innovation} Adoption Research

Why do some firms take the lead in adopting IT innovations while others lag? This is a central question in the IT innovation diffusion field, one that researchers have addressed by formulating models wherein a set of explanatory factors (e.g., organizational structure, resources, competitive environment) are used to predict the timing and extent of innovation adoption (Fichman 2004b). These factors can be used to identify the profile of innovation leaders (and laggards) in some context. For example, technological infrastructure and technological experience were found to be important innovation profile dimensions in the context of IS development process innovations such as programmer teams and data flow diagrams (Mustonen-Ollila and Lyytinen 2004).

Prior research seeking to identify adoption antecedents has been guided by a great diversity of reference theories, including those based on economic rationality, competitive effects, organizational learning, institutional theory, the resource-based view of the firm, complementarities, and many others. Nevertheless, this stream has been dominated by an economic-rationalistic logic wherein the firms expected to take the lead in practice are those that normatively should lead (Fichman 2004). Sometimes the rationales for predictor variables are explicitly economic. But more often, rationales 
revolve around one or both of two implicitly economic themes, one concerning a firm's ability to adopt, and the other concerning a firm's degree of innovation-related needs and/or opportunities. Firms with a greater ability to adopt would be expected to have a more effective implementation (e.g., configuring the technology properly, getting the right people to use it, making appropriate complementary investments in organizational change), which suggests they are likely to get greater benefits from any given level of use. Similarly those with greater needs or opportunities related to an innovation should derive greater benefits from some level of use. (See Table 1 for a summary of how a representative sample of often-studied innovation antecedents relate to abilities and needs). A criticism of the dominant paradigm is that the normative assumption does not always hold - some firms that normatively should take the lead do not, and vice versa which is our central motivating issue.

Table 1: Representative Antecedents of IT Innovation Adoption

\begin{tabular}{|l|l|}
\hline Construct & Description and Linkage to Ability to Adopt \& Innovation Needs \\
\hline Organizational & $\begin{array}{l}\text { Proxy for other variables that are positively related to innovation, including scale, } \\
\text { slack resources, professionalism and specialization (Tornatzky and Fleischer 1990, } \\
\text { pg. 162). A larger scale of activities promotes the ability to amortize innovation } \\
\text { costs (Fichman and Kemerer 1997). Slack resources allow an organization to bear } \\
\text { the costs of instituting innovations and to absorb setbacks along the way } \\
\text { (Damanpour 1991). Professionalism increases boundary-spanning activity, } \\
\text { self-confidence, and a commitment to move beyond the status quo (Damanpour } \\
\text { 1991). Greater variety of specialists provides a broader knowledge base and } \\
\text { increases the cross-fertilization of ideas (Damanpour 1991). }\end{array}$ \\
\hline $\begin{array}{l}\text { Top } \\
\text { Management }\end{array}$ & $\begin{array}{l}\text { Top managers are responsible for allocating appropriate resources to an } \\
\text { innovation effort, aligning incentives, monitoring progress towards goals, and } \\
\text { intervening to get innovation projects back on track (Sharma and Yetton 2003). } \\
\text { Supportive managers are more likely to engage in these innovation management } \\
\text { tasks. Also, top managers are more likely to support innovation projects they see as } \\
\text { well-aligned with a firm's strategic needs and abilities (Huigang et al. 2007). }\end{array}$ \\
\hline Compatibility & $\begin{array}{l}\text { Innovations that are more compatible with existing strategies, technologies, needs } \\
\text { and values require fewer organizational changes to implement and are less likely to } \\
\text { provoke resistance, resulting in lower costs and less risk of underutilization or } \\
\text { failure. More compatible technologies should also have greater complementarities, } \\
\text { leading to magnified innovation returns (Zhu 2004). }\end{array}$ \\
\hline $\begin{array}{l}\text { Organizational } \\
\text { Knowledge and } \\
\text { Skill }\end{array}$ & $\begin{array}{l}\text { Organizations with greater knowledge and skill are more likely to recognize when } \\
\text { an innovation is likely beneficial, have lesser costs associated with organizational } \\
\text { learning, and are more likely to make good decisions throughout the innovation } \\
\text { process (Fichman and Kemerer 1997). }\end{array}$ \\
\hline
\end{tabular}




\subsection{Beyond the Dominant Instrumental Logic}

Models of innovation adoption often reflect a normative stance in that they rely on rationales that link innovation to abilities or needs. When a prediction model incorporates factors that capture (or at least correlate with) innovative abilities, then firms positioned favorably on these factors (i.e., firms that fit the profile of an innovator) are better-positioned to profit from being a leading adopter, because they are more likely to have an abundance of resources and expertise to apply to the effort. This is important, because innovation is not easy. While the decision to adopt requires no special talent, the path from adoption to assimilation and then on to captured business value presents a series of challenges and potential obstacles (Avison et al. 2006). Firms may choose the wrong instance of the technology, or improperly configure it, or install it badly, or find the intended users resist it, or fail to make crucial complementary changes to the surrounding organization (Brynjolfsson and Hitt 2000; Melville et al. 2004b). Firms with higher innovative abilities should be more likely to skillfully navigate these obstacles and achieve deeper and more effective assimilation at lower cost, resulting in higher innovation returns.

Firms that innovate despite having an innovation profile suggestive of a laggard-i.e., those with an over-adoption type misfit-are less likely to be able to translate the adoption decision into thorough assimilation and positive organizational impacts. Such firms tend to have fewer resources, less expertise, and cultures and structures that are less conducive to innovation. The net result for them should be higher costs, lower benefits, and so diminished returns to innovation.

Similar patterns should be observed to the extent the innovation prediction model includes variables that tap into innovation needs/opportunities. In this case, firms that rate favorably on these factors are positioned to derive greater benefits from being an adoption leader, virtually by definition. Such firms are more likely to have a high degree of compatibility between the innovation and their strategies, processes, values and skills, and to operate in industries where the innovation is particularly well-suited. Also, they should be more persistent in their assimilation efforts because they quite rightly foresee a greater potential reward at the end of the road. On the other hand, firms that are poorly 
positioned on variables that capture innovation needs and opportunities may be more prone to having their commitment drain away as obstacles are encountered, and as realization dawns that perhaps the firm is not the best candidate for innovation leadership after all. Should assimilation be achieved despite obstacles, the innovation returns will tend to be diminished owing to the relative lack of needs for the innovation or opportunities to exploit it. ${ }^{1}$

The above arguments suggest that when a theoretical model of innovation is based on an instrumental logic — and most are_-firms exhibiting a high fit between expected and actual innovation should have higher returns to innovation than those with an overadoption misfit (i.e., firms with the profile of a laggard but the adoption behavior of a leader).

We now explicate the implications of under-adoption innovation misfits. Such firms pay an opportunity cost in that they have a lower level of adoption-and so a lower level of adoption-driven benefits - than peer firms that “right-adopted.” However, the issue of the extent to which being an under-adopter affects the returns to any given level of adoption is more nuanced relative to the case of over-adoption misfit. On the one hand, such firms might be viewed as being well qualified on a structural level—if not over qualified - for the level of adoption they have chosen. Unlike over-adopters, which as argued above would tend to lack the resources and expertise needed to translate adoption into business value, under-adopters would occupy a position on the innovation profile relative to their own behavior suggesting a greater abundance of resources and expertise than even right-adopting peers. On the other hand, this sort of misfit is evidence of a lack of mindfulness among decision makers about innovation timing (Swanson and Ramiller 2004). If managers are not mindful in deciding when to adopt, perhaps they will also be less mindful in other decisions related to IT implementation and use. For example, although they may possess latent resources and expertise that could smooth the implementation process, they may be less likely to deploy those resources appropriately.

\footnotetext{
${ }^{1}$ For the sake of argument, we have talked about factors that relate to abilities versus needs as if they were different factors leading to different prediction models. In reality, many antecedents of organizational innovation can be related to both abilities and needs, and in practice antecedents tend to be correlated. For example, firms that have greater needs (e.g., they operate in a more information-intensive industry) are more likely to develop greater innovative abilities (e.g., by hiring more skilled IT personnel).
} 
As a result, while we theorize a clear negative relationship between over-adoption type misfit and returns to innovation, we see a more complex relationship between underadoption misfit and innovation returns. We address the issue of how over- and underadoption affect innovation returns in more detail when we present our conceptual model and hypotheses in the next section. First, we provide additional conceptual and theoretical foundations related to the origin of innovation misfits.

\subsection{Conceptual \& Theoretical Considerations}

Swanson and Ramiller (2004) develop the concept of innovation mindfulness, which they treat as an emergent property of an organization that derives in part from the mindfulness of individual managers. They classify an organization as innovating mindfully when it "attends to innovation with reasoning grounded in its own facts and specifics,” and further explain that these situational specifics “... can be quite complex, including, among other issues, the innovation's ramifications for operational efficiencies and strategic advantage; the organization's preparedness for the change involved; the quality and availability of complementary resources needed; implications for various common and conflicting interests, both internally and in interfirm relationships; and the effects of adoption on the firm's legitimacy with outside constituencies” (pg. 4). A mindless organization, by contrast, makes adoption decisions without a reasoning grounding in these situational specifics. Most of these situational specifics have an obvious normative interpretation related to innovation abilities or needs/opportunities. Moreover, these situational specifics pertain to managerial decision-making throughout the adoption and implementation process. We believe it would be unusual-though of course not impossible-for a firm that was very mindful in identifying they had the sorts of resources and capabilities required to take on the challenge of being an innovation leader-but then mindlessly ignore those resources and capabilities in crafting the actual implementation strategy.

In sum, these definitions suggest a strong linkage between innovation mindfulness and innovation fit. In particular, we expect that mindful organizations will be more likely to seek a state where there is a good fit between their specific characteristics and actual innovation behavior, and will hence be less prone to experience inadvertent innovation 
misfits. By contrast, the mindless organization should be highly prone to such misfits. Thus, the mindfulness construct informs and overlaps with the fit construct, though the two remain conceptually distinct. ${ }^{2}$

Mindless innovation can arise from a number of causal mechanisms, including institutional isomorphism (the tendency of organizations to come to resemble each other more than they should from an instrumental standpoint (DiMaggio and Powell 1983)), information cascades (the tendency of decision makers to base choices on observations of others' choices more so than private information (Bikhchandani et al. 1998)) and managerial fashions (the tendency of organizations to adopt innovations that are the most prominent topics of discourse (Abrahamson 1996)). Though the mechanisms differ, these perspectives all provide explanations for why some firms might tend to go along with the pack without giving much attention to situational specifics as a factor in innovation decisions.

\section{Conceptual Model \& Hypothesis Development}

We formalize arguments pertaining to innovation misfit in a conceptual model (Figure 1, Table 2).

Figure 1: Conceptual Model

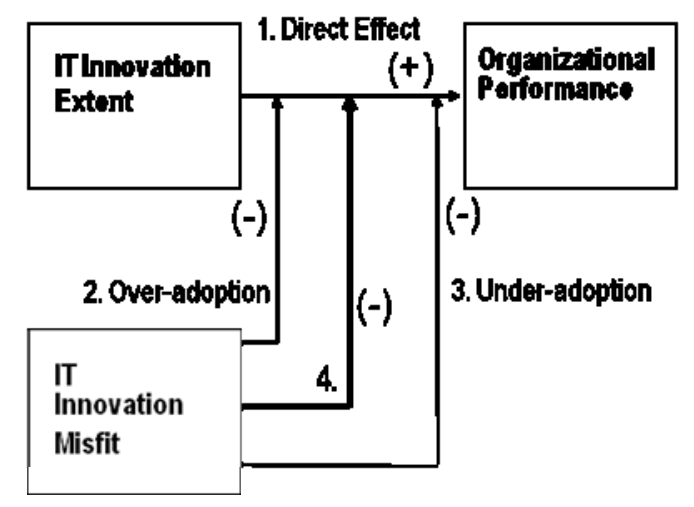

\footnotetext{
${ }^{2}$ Mindfulness is a cognitive element predominantly associated with a process, while innovation fit is a structural element associated with a firm's innovation profile. Also, unmindful managers can accidentally achieve a high level of fit, and mindful managers can choose to attend to certain specifics (e.g., implications of adoption for their own prestige) that do not necessarily relate to instrumental impacts of adoption. Nevertheless, where mindlessness is pervasive, we expect that innovation misfits will follow. This means that the conditions that lead to more pervasive mindless adoption should also lead to more pervasive innovation misfits.
} 
Table 2: Conceptual Model Constructs

\begin{tabular}{|l|l|}
\hline \multicolumn{1}{|c|}{ Construct } & \multicolumn{1}{c|}{ Definition } \\
\hline IT Innovation Extent & $\begin{array}{l}\text { Degree to which a firm adopts a set of IT innovations earlier and more } \\
\text { extensively. }\end{array}$ \\
\hline IT Innovation Misfit & $\begin{array}{l}\text { Degree of misalignment between a firm's normative IT innovation } \\
\text { profile and actual IT innovation extent. }\end{array}$ \\
\hline $\begin{array}{l}\text { Organizational } \\
\text { Performance }\end{array}$ & Performance of the organization \\
\hline
\end{tabular}

The rationale for a positive association between IT innovation and organizational performance (Figure 1, Link \#1) is based on theoretical considerations as well as a large body of prior research. At the most basic level, the adoption of innovative IT can be viewed as creating a particular kind of IT capital. According to micro-economic theory, a rational firm should invest in any particular form of capital just to the point where the last unit of investment produces no more value than it costs; since costs of IT capital are positive, the gross marginal productivity contribution of IT should likewise be positive (Hitt and Brynjolfsson 1996). A large number of studies have verified a positive link between IT capital and productivity, both when IT is defined as aggregated IT investment (Brynjolfsson and Hitt 1996) and when it is defined as the use of some particular technology (Barua et al. 2004; Hitt et al. 2002; Mukhopadhyay et al. 1997). Although additional arguments can be developed for why IT innovation adoption should improve productivity (for example, IT innovations might enable a more efficient organization of production) the interpretation of IT innovation as producing a specialized form of capital suffices for our current purpose. ${ }^{3}$

H1: There is a positive association between IT innovation extent and organizational performance, ceteris paribus.

Now consider the implications of innovation misfit-the degree of misalignment between the extent to which a firm is innovating versus the extent to which it is

\footnotetext{
${ }^{3}$ Hypothesis 1 does not imply that more IT is always better. For example, while technology should improve productivity in general, it comes at a cost, and it is certainly possible for the cost to exceed the productivity improvement for some adopters. Also, what holds in the general case need not be seen in every individual case.
} 
theoretically expected to be innovating — for firm performance. In the general case, a mindful firm that seeks normatively rational outcomes will attempt to choose a level of innovation that reflects its relative position on the innovation profile. A firm whose innovation profile is indicative of the greatest abilities and needs with respect to the innovation will usually be best served to take the lead, while a firm that has the profile of a laggard will usually be best served to defer adoption or to adopt less extensively.

To make things more concrete, imagine a hypothetical example of an emerging IT for which the normative profile of an innovator is dominated by just one factor: firm size. Perhaps this technology is most suitable for large-scale production and requires the kind of professionalism and expertise that is most often found in large firms. Suppose that two firms have adopted relatively early, one large and one small. The large firm would be a right-adopter with a high degree of innovation fit, while the small firm would be an over-adopter. Of the two firms, we would expect the right-adopting large firm to have greater returns to innovation than the over-adopting small firm. The large firm is well suited to innovating in the early part of the overall diffusion cycle, but the small firm is poorly suited to it. In particular, the small firm is at a structural disadvantage (due to a lower production scale) and also has a greater risk of an excessively costly and poor quality implementation (due to the lack of expertise). The small firm might still get some productivity enhancement from adoption, but less than the large firm with the more appropriate production scale. It is easy to imagine this sort of scenario happening in practice with such complex IT as electronic networking technologies in manufacturing plants.

In addition to the structural disadvantage just described, over-adoption implies a lack of innovation mindfulness. In this hypothetical situation, the key organizational fact for managers to attend to in making the adoption decision is firm size, and yet the behavior of the small firm suggests they did not attend to it. This, in turn, would suggest that a firm-level over-adoption misfit is not only evidence of a structural disadvantage, but also an indicator of a potential implementation execution disadvantage arising from mindlessness, which should also tend to lower innovation returns. 
Though not a required condition for our hypothesis to hold, it is interesting to consider the potential logical linkage between mindlessness in adoption timing and mindlessness during implementation. Swanson and Ramiller (2004) define innovation mindfulness as a general property of an organization in its engagement with a technology that derives in large part (but not exclusively) from the mindfulness of its managers. In most organizations the same managers (e.g., IT executives and those in affected line functions) are involved in decisions about when or whether to adopt, and also about what resources are needed and available to effect a successful implementation. It is certainly possible for the same managers to be unmindful about linking available resources to the adoption decision and mindful in linking available resources to implementation (or the converse). It is also possible that managers who drove the initial adoption decision were unmindful, but then transferred the project to mindful managers to run the implementation. In practice, we think such situations are likely to be the exception rather than the rule, suggesting that mindlessness in adoption timing will be positively associated (but by no means perfectly correlated) with mindlessness during the implementation process. ${ }^{4}$ To sum up, to the extent that mindlessness pervades the innovation process and is reflected in the firm's level of over-adoption misfit, this suggests returns will be even further lowered among firms with an over-adoption misfit due to a greater likelihood of poor implementation execution. These arguments lead to our second hypothesis (Figure 1, Link \#2):

H2: The positive association between IT innovation extent and organizational performance is negatively moderated by over-adoption innovation misfit.

While the performance implications of over-adoption misfit are relatively straightforward, the effects of under-adoption misfit are more complex. Returning to our hypothetical emerging technology, assume a pair of late-adopting firms, one large and one small. In this case, the small firm will be classified as a right-adopter with a high innovation fit (innovation profile of a laggard paired with late adoption), while the large firm will have an under-adoption type misfit (innovation profile of a leader paired with

\footnotetext{
${ }^{4}$ See Zorn (2002) for an unusually frank insider account of an IT innovation adoption and implementation process in the context of web-based case management that details the salience of discourse, politics, and emotion and broadly supports our logic.
} 
late adoption). The under adopting firm pays an opportunity cost in that it is using a beneficial technology at a lower level than it theoretically could or should. However, the impact of under-adoption on the returns to any given level of innovation will be ambiguous. On the one hand, the large firm should be in a better structural position to adopt, as evidenced by a profile (large size) consistent with innovation leadership. Even though we are now looking at adoptions occurring at a later point in the diffusion cycle-where the innovation has come within the economic reach of smaller firmsthere should still be some structural size advantage. On the other hand, there is evidence of a lack of mindfulness in the large firm in timing the adoption decision, which (as argued above for the case of over-adoption) may be associated with reduced mindfulness during implementation and thus increase the chance of implementation execution problems. Case studies of IT projects showing multiple dimensions of poor performance for a given project are consistent with this logic (Nelson 2007). For example, resources may exist in abundance but not be properly allocated to the implementation project because managers, who unmindfully missed the link between resource availability and adoption timing, carried this aspect of mindlessness forward into the implementation.

To summarize, under-adoption misfit will lead to two effects. Such firms will tend to be structurally well positioned to get good innovation returns but are less likely to be mindful in terms of project execution, which tends to lower returns. On balance, we think that the latter effect will dominate the former effect, given the severe implications of adoption without mindfulness (Figure 1, Link \#3).

H3: The positive association between IT innovation extent and organizational performance is negatively moderated by under-adoption innovation misfit.

Given our arguments for over-adoption innovation misfit and under-adoption innovation misfit, we hypothesize that taken together, IT innovation misfit has negative moderation implications for the link between IT and performance (Figure 1, Link \#4).

H4: The positive association between IT innovation extent and organizational performance is negatively moderated by innovation misfit. 


\section{Research Methodology}

\subsection{Data}

The dataset used to estimate our econometric models was constructed by combining three separate internal datasets collected and maintained by the U.S. Census Bureau. These datasets represent the most comprehensive and accurate measurement of the U.S. manufacturing sector and are widely used to study innovative activity and productivity (Atrostic and Nguyen 2005; Bartelsman and Doms 2000; Dunne et al. 2000; McElheran 2008; Power 1998). The Census of Manufactures (CM) includes numerous economic variables on the universe of U.S. manufacturing establishments-more than 300,000 in 1997_for years ending in numerals 2 and 7, including revenue, payroll, employees, cost of materials, value of shipments, capital stock, etc. ${ }^{5}$ The Annual Survey of Manufacturers (ASM) spans years between Census years and comprises CM variables and others for a stratified sample of manufacturing establishments (roughly 50,000 in 1997).

The source of data for the core IT adoption variable employed in this study is the 1999 ASM Computer Network Use Supplement (CNUS). CNUS contains data on a range of electronic networking technologies (ENT) in use at the plant, including various technologies intended to improve firm efficiency, such as the use of the Internet, electronic data interchange, and intranets. Matching the 1997 CM, 1999 ASM, and 1999 CNUS yields 26,992 manufacturing plants.

\subsection{Econometric Model}

We develop a plant-level model to determine the antecedents of ENT adoption (Cooper and Zmud 1990; Fang et al. 2005; Ramamurthy et al. 2008). ${ }^{6}$ For the dependent variable, prior research has often employed binary adoption measures of a single technology, such as electronic data interchange (Premkumar and Ramamurthy 1997) and extent of usage measures, such as revenue from Internet divided by total revenue (Hong and Zhu 2006). To capture a fuller range of innovative activity our dependent variable (ENT) comprises

\footnotetext{
${ }^{5}$ See Jarmin and Miranda (2002) for details.

${ }^{6}$ We cannot jointly estimate adoption and performance models given that the output of the adoption prediction model is required to compute an independent variable included in the plant performance model.
} 
the use of multiple electronic networking technologies captured in the CNUS (Atrostic 2007). Specifically, ENT is measured as the sum of six electronic networking technology items capturing “use/don’t use”: internet, intranet, extranet, local area networks, electronic data interchange, other networks. ${ }^{7}$

We predict innovative extent using a set of independent variables based on findings from prior research (Table 3). IT innovation is challenging and requires skilled employees to execute successfully, so we include worker skill (SKILL) (Atrostic and Nguyen 2005; Colombo and Mosconi 1995; Doms et al. 1997). Since newer plants may have the ability to leapfrog older information technology infrastructure (Dunne 1994), we include plant age in years (AGE). We also include plant size (SIZE) and whether the plant is part of a multi-plant firm (MULTI), given that larger firms and multi-plant firms tend to have managers that are more professional and sophisticated (Armstrong and Sambamurthy 1999). In sum, our adoption antecedent model, which contains these four variables and a control for industry $(C O N T R O L)$ is expected to explain a reasonable amount of variance in ENT given the findings of prior research. The model is presented in Equation (1) below:

$$
E N T=\beta_{0}+\beta_{1} S K I L L+\beta_{2} A G E+\beta_{3} S I Z E+\beta_{4} M U L T I+C O N T R O L+\varepsilon
$$

After estimation, we use the residuals to determine innovation misfit (MF): 1 if residuals are in the top or bottom 25 percentile, and 0 otherwise. Analogously, we compute overadoption misfit (MFO) for the top 25 percentile of residuals and under-adoption misfit $(M F U)$ as the bottom 25 percentile of residuals. The use of residuals to form a misfit or mismatch variable builds on prior research employing this approach (Bollingtoft et al. 2009; Meilich 2006). For example, Ittner et al. (2002) use a multivariate regression predicting activity-based costing (ABC) adoption to compute two separate measures of misfit using positive residuals and negative residuals, which were subsequently used as predictors in manufacturing plant performance regressions. Similarly, Dewar and

\footnotetext{
${ }^{7}$ Our use of an aggregate measure does not assume that each kind of technology should necessarily have an equal impact on productivity, nor does it assume that the incremental impact of increasing from, say, one to two technologies in use should be exactly the same as the incremental impact of increasing from four to five in use. Nonetheless, principal component analysis (PCA) on the ENT components indicates that each technology has a similar loading on the aggregate measure, lending further support to our use of ENT as a broad measure of IT innovation.
} 
Werbel (1979) use the absolute value of residuals derived from regressions of structure and control variables on the routineness of technology as measures of misfit.

Table 3: Construct Operationalization

\begin{tabular}{|c|c|c|c|}
\hline Construct & Variable & Operationalization & Citations \\
\hline \multicolumn{4}{|c|}{ ADOPTION ANTECEDENT MODEL } \\
\hline $\begin{array}{l}\text { Innovation } \\
\text { Extent }\end{array}$ & ENT & $\begin{array}{l}\text { Electronic networking } \\
\text { technologies. Sum of six } \\
\text { dichotomous items - "Do you } \\
\text { use x technology?" - where x is } \\
\text { LAN, EDI, internet, extranet, } \\
\text { intranet, other. }\end{array}$ & $\begin{array}{l}\text { (Hong and Zhu 2006; } \\
\text { Iacovou et al. 1995; } \\
\text { Mishra and Park 2005) }\end{array}$ \\
\hline Worker Skill & SKILL & $\begin{array}{l}\text { Ratio of non-production labor to } \\
\text { total labor. }\end{array}$ & $\begin{array}{l}\text { (Atrostic and Nguyen } \\
\text { 2005; Colombo and } \\
\text { Mosconi 1995; Doms et al. } \\
\text { 1997) }\end{array}$ \\
\hline Plant Age & $A G E$ & $\begin{array}{l}\text { Time since plant opened, in } \\
\text { years. }\end{array}$ & $\begin{array}{l}\text { (Atrostic and Nguyen } \\
\text { 2005; Colombo and } \\
\text { Delmastro 2002; Dunne } \\
\text { 1994) }\end{array}$ \\
\hline Plant Size & SIZE & $\begin{array}{l}\text { Log of total employees at the } \\
\text { plant. }\end{array}$ & $\begin{array}{l}\text { (Astebro 2002; Atrostic } \\
\text { and Nguyen 2005; } \\
\text { Colombo and Delmastro } \\
\text { 2002) }\end{array}$ \\
\hline $\begin{array}{l}\text { Multi-Plant } \\
\text { Firm } \\
\end{array}$ & MULTI & $\begin{array}{l}\text { Plant is part of a multi-plant firm } \\
\text { (yes/no). }\end{array}$ & $\begin{array}{l}\text { (Atrostic and Nguyen } \\
\text { 2005) }\end{array}$ \\
\hline Control & $\begin{array}{l}\text { CONTRO } \\
L\end{array}$ & $\begin{array}{l}\text { Industry control variables (20) } \\
\text { computed at 3-digit NAICS } \\
\text { level. }\end{array}$ & Convention. \\
\hline \multicolumn{4}{|c|}{ PLANT PERFORMANCE MODEL } \\
\hline $\begin{array}{l}\text { Plant } \\
\text { Performance }\end{array}$ & $L P$ & $\begin{array}{l}\text { Labor productivity as measured } \\
\text { by ratio of total value of } \\
\text { shipments to total employment. }\end{array}$ & $\begin{array}{l}\text { (Black and Lynch 2001; } \\
\text { Bresnahan et al. 2002; } \\
\text { Melville et al. 2004; Oliner } \\
\text { and Sichel 2002) }\end{array}$ \\
\hline $\begin{array}{l}\text { Innovation } \\
\text { Misfit }\end{array}$ & MF & $\begin{array}{l}\text { Degree of misalignment } \\
\text { between a firm’s normative } \\
\text { innovation profile and actual } \\
\text { innovative activity using } \\
\text { residuals from adoption } \\
\text { antecedent model. }\end{array}$ & $\begin{array}{l}\text { (Bollingtoft et al. 2009; } \\
\text { Dewar and Werbel 1979; } \\
\text { Ittner et al. 2002; Meilich } \\
\text { 2006) }\end{array}$ \\
\hline $\begin{array}{l}\text { Capital } \\
\text { Intensity }\end{array}$ & $K L$ & Ratio of capital to total labor. & $\begin{array}{l}\text { (Atrostic and Nguyen } \\
\text { 2005) }\end{array}$ \\
\hline $\begin{array}{l}\text { Material } \\
\text { Intensity }\end{array}$ & $M L$ & $\begin{array}{l}\text { Ratio of materials expense to } \\
\text { total labor. }\end{array}$ & $\begin{array}{l}\text { (Atrostic and Nguyen } \\
\text { 2005) }\end{array}$ \\
\hline Control & $\begin{array}{l}\text { CONTRO } \\
L\end{array}$ & $\begin{array}{l}\text { Industry control variables (21) } \\
\text { computed at 3-digit NAICS } \\
\text { level. Size control variables (6) } \\
\text { based on SIZE variable. }\end{array}$ & Convention. \\
\hline
\end{tabular}


Improving productivity has been an important role of innovative activity associated with information systems (Black and Lynch 2001; Bresnahan et al. 2002; Melville et al. 2004; Oliner and Sichel 2002), so we use labor productivity (LP) as our measure of plant performance. Similar to prior research examining the productivity implications of information technology (Atrostic and Nguyen 2005; Black and Lynch 2001), we predict labor productivity using the capital-labor ratio $(K L)$, materials-labor ratio $(M L)$, and controls for size and industry (CONTROL). To test developed hypotheses, we also include an interactive term of misfit $(M F)$ and electronic networking technologies (ENT), as well as main effects of each. Our generic plant performance model is presented in Equation (2) below:

$$
L P=\beta_{0}+\beta_{1} E N T+\beta_{2} M F+\beta_{3} M F \times E N T+\beta_{4} K L+\beta_{5} M L+C O N T R O L+\varepsilon
$$

In the performance equation (2), the estimated coefficient on the interactive term is used to assess H2, while that on ENT is used to assess H1. Analogous estimation models are employed that use $M F O$ and $M F U$ to test $\mathrm{H} 2$ and $\mathrm{H} 3$.

\subsection{Descriptive Statistics}

Descriptive statistics and a correlation matrix are presented in Table 4. We compute the mean and standard deviation for the whole dataset $(\mathrm{N}=26,992)$ as well as for low ENT (0-2) and high ENT (3-6) subsamples. As expected, ENT has a positive correlation with skill and size. Labor productivity is positively and significantly correlated with capital intensity, materials intensity, and ENT. In addition, the mean values for productivity model predictors are higher in the high ENT subsample than in the low ENT subsample. For example, $K L$ is 82.14 for low ENT and 132.97 for high ENT.

\section{Empirical Findings}

\subsection{Estimation Results}

The dependent variable in our adoption antecedent model (1) represents a count of technologies in use. We thus use a count model for estimation, consistent with prior literature assessing the antecedents of counts of various information technologies (Mishra and Park 2005). Based on the Akaike Information Criterion (AIC) and Bayesian 
Information Criterion (BIC) fit criteria, we adopt the Poisson model rather than the negative binomial model (Long 1997). The Poisson regression model posits that the mean of the number of adopted technologies is conditional on plant-level characteristics according to an exponential function. As a robustness check, we approximate the Poisson regression model by logging both sides of the regression equation, which leaves us with the log of ENT as the dependent variable and a linear equation on the right-hand side (Long 1997). Given that the log of zero is undefined, we must increment ENT; we choose an increment of .025, given that increments of .5 and .01 are commonly used in the literature. We estimate this approximation using ordinary least squares (OLS) regression.

Table 4: Descriptive Statistics and Correlation Matrix

\begin{tabular}{|c|c|c|c|c|c|c|c|c|c|c|c|}
\hline & \multicolumn{3}{|c|}{ MEAN (SD) } & \multicolumn{8}{|c|}{ CORRELATION COEFFICIENT } \\
\hline & $\begin{array}{c}\text { All } \\
\mathrm{N}=\mathbf{2 6 9 9 2}\end{array}$ & $\begin{array}{c}\text { Low ENT } \\
\mathrm{N}=13834\end{array}$ & $\begin{array}{c}\text { Hi ENT } \\
\mathbf{N}=13158\end{array}$ & 1 & 2 & 3 & 4 & 5 & 6 & 7 & 8 \\
\hline 1. ENT & $\begin{array}{c}2.46 \\
(1.165) \\
\end{array}$ & $\begin{array}{c}1.50 \\
(.5667) \\
\end{array}$ & $\begin{array}{c}3.47 \\
(.6668) \\
\end{array}$ & 1 & & & & & & & \\
\hline 2. SKILL & $\begin{array}{c}.2798 \\
(.1833) \\
\end{array}$ & $\begin{array}{c}.2754 \\
(.1812) \\
\end{array}$ & $\begin{array}{c}.2843 \\
(.1854) \\
\end{array}$ & $.0393 *$ & 1 & & & & & & \\
\hline 3. $A G E$ & $\begin{array}{c}20.25 \\
(7.070)\end{array}$ & $\begin{array}{c}19.70 \\
(7.196)\end{array}$ & $\begin{array}{c}20.83 \\
(6.888) \\
\end{array}$ & $.0783 *$ & -.0149 & 1 & & & & & \\
\hline 4. SIZE & $\begin{array}{c}242.49 \\
(465.90)\end{array}$ & $\begin{array}{c}135.82 \\
(195.78)\end{array}$ & $\begin{array}{c}354.64 \\
(616.82)\end{array}$ & $.2926^{*}$ & $-.0248 *$ & $.1052 *$ & 1 & & & & \\
\hline 5. MULTI & $\begin{array}{c}.6967 \\
(.4597) \\
\end{array}$ & $\begin{array}{c}.5559 \\
(.4969) \\
\end{array}$ & $\begin{array}{c}.8448 \\
(.3621) \\
\end{array}$ & $.3196 *$ & $-.0530 *$ & $.1089 *$ & $.2065 *$ & 1 & & & \\
\hline 6. $L P$ & $\begin{array}{c}281.95 \\
(383.39) \\
\end{array}$ & $\begin{array}{c}233.95 \\
(308.48) \\
\end{array}$ & $\begin{array}{c}332.41 \\
(443.30) \\
\end{array}$ & $.1185^{*}$ & $.0696 *$ & .0098 & $.0329 *$ & $.2037 *$ & 1 & & \\
\hline 7. $K L$ & $\begin{array}{c}106.92 \\
(221.72)\end{array}$ & $\begin{array}{c}82.14 \\
(204.60)\end{array}$ & $\begin{array}{c}132.97 \\
(235.60)\end{array}$ & $.1072 *$ & $.0378^{*}$ & $.0245 *$ & $.0355^{*}$ & $.1563 *$ & $.4795 *$ & 1 & \\
\hline 8. $M L$ & $\begin{array}{c}151.89 \\
(257.31)\end{array}$ & $\begin{array}{c}125.23 \\
(208.97)\end{array}$ & $\begin{array}{c}179.91 \\
(297.29)\end{array}$ & $.0935 *$ & $.0488 *$ & .0042 & $.0249 *$ & $.1854 *$ & $.8757 *$ & $.4268 *$ & 1 \\
\hline
\end{tabular}

${ }^{*} \mathrm{p}<.01$; Values are not logged. $L P, K L$, and $M L$ in $\$ 1000 /$ employee.

Estimation results for the adoption prediction model (1) are presented in the first two columns of Table 5. We use heteroscedasticity consistent standard errors to enable consistent inference in the presence of potential heteroscedasticity. For both models, the predictors have good explanatory power as all are significant at the .01 level. Estimates across the two specifications are consistent in sign and significance with expectations, further supporting the validity of the models. For the case of OLS, the model explains $21 \%$ percent of the variance in $\log (E N T)$. The Poisson model was statistically significant, with a log-likelihood of $-42,330$, negative BIC supporting the chosen model 
over the saturated model, and small AIC indicating a plausible model. Moreover, we used various diagnostics (included in Stata's counfit procedure) to determine that the Poisson model is preferred over the zero-inflated Poisson model. Inspection of residuals from both models indicates that they are approximately normally distributed, consistent with a correctly specified model (though not required for consistent coefficient estimates).

In the case of OLS, computing residuals, $M F, M F O$, and $M F U$ is straightforward. In the case of the Poisson model, there is a choice of residual types and we use deviance residuals, as suggested in the literature (McCullagh and Nelder 1989). Examining crosstabulations between misfit (MF) computed from the OLS versus the Poisson specification reveals a strong overlap, with $97 \%$ of plants being classified the same, further supporting the robustness of our adoption antecedent model across alternative estimation approaches. In the following, we use Poisson-generated misfit classifications, and rerun using OLS-generated classifications for robustness. Finally, cross-tabulations of ENT and MF indicate that misfit firms are distributed across different levels of ENT. For example, more than half of plants that are low in ENT $(<=2)$ are not under-adoption misfits, while more than one-third of plants that are high in ENT (=4) are not overadoption misfits.

Following estimation of the adoption prediction model and computation of misfit dummy variables, we estimate the plant performance model in (2). First, we use sample splits on MF and examine the differences in ENT coefficient estimates across the fit and misfit categories. According to H1, we would expect the coefficient on ENT to be positive and significant, which is indeed the case (Table 5, columns 3 and 4). Additionally, we observe that the coefficient on ENT is significantly larger on the fit category versus the misfit category, consistent with H4. The coefficient on ENT for no misfit is .06 whereas for fit it is much smaller (.03). Examination of 95\% confidence intervals reveals that there is clearly a statistically significant difference between the two parameter estimates. 
Table 5: Adoption Prediction Estimation \& Productivity Estimation Sample Splits

\begin{tabular}{|c|c|c|c|c|c|c|}
\hline & \multicolumn{2}{|c|}{$\begin{array}{c}\text { Adoption Antecedent } \\
\text { Model }\end{array}$} & \multicolumn{4}{|c|}{ Productivity Model (Split Sample) } \\
\hline & & & No Misfit & Misfit & No Misfit & Misfit \\
\hline & OLS & Poisson & OLS & OLS & IV & IV \\
\hline SKILL & $\begin{array}{l}.0516^{*} \\
(.0048)\end{array}$ & $\begin{array}{l}.0504^{*} \\
(.0061)\end{array}$ & & & & \\
\hline AGE & $\begin{array}{l}-.0015^{*} \\
(.0004)\end{array}$ & $\begin{array}{l}-.0015+ \\
(.0006)\end{array}$ & & & & \\
\hline SIZE & $\begin{array}{l}.1584 * \\
(.0030)\end{array}$ & $\begin{array}{l}.1523^{*} \\
(.0038)\end{array}$ & & & & \\
\hline MULTI & $\begin{array}{l}.1865 * \\
(.0075) \\
\end{array}$ & $\begin{array}{l}.2019^{*} \\
(.0103)\end{array}$ & & & & \\
\hline ENT & & & $\begin{array}{l}.0587^{*} \\
(.0062)\end{array}$ & $\begin{array}{l}.0329 * \\
(.0023)\end{array}$ & $\begin{array}{l}.2222^{*} \\
(.0500)\end{array}$ & $\begin{array}{l}.0488^{*} \\
(.0075)\end{array}$ \\
\hline KL & & & $\begin{array}{l}.0839 * \\
(.0039)\end{array}$ & $\begin{array}{l}.0834^{*} \\
(.0041)\end{array}$ & $\begin{array}{l}.0782^{*} \\
(.0044)\end{array}$ & $\begin{array}{l}.0810^{*} \\
(.0042)\end{array}$ \\
\hline ML & & & $\begin{array}{l}.5480^{*} \\
(.0062)\end{array}$ & $\begin{array}{l}.5823^{*} \\
(.0060)\end{array}$ & $\begin{array}{l}.5374 * \\
(.0067)\end{array}$ & $\begin{array}{l}.5795^{*} \\
(.0061)\end{array}$ \\
\hline Const. & $\begin{array}{c}.0508 \\
(.0332) \\
\end{array}$ & $\begin{array}{l}-.0175 \\
(.0312) \\
\end{array}$ & $\begin{array}{l}2.682^{*} \\
(.0513)\end{array}$ & $\begin{array}{l}2.1618 \\
(.0481)\end{array}$ & $\begin{array}{l}1.822^{*} \\
(.1432)\end{array}$ & $\begin{array}{l}2.126^{*} \\
(.0360)\end{array}$ \\
\hline $\mathbf{N}$ & 26,992 & 26,992 & 14,791 & 12,201 & 14,791 & 12,201 \\
\hline $\mathbf{R}^{2}$ & 2072 & & .7818 & .8167 & .7709 & .8159 \\
\hline $\begin{array}{l}\text { F-stat/ } \\
\text { Wald }\end{array}$ & $323.82 *$ & & $1067.47^{*}$ & $1101.74 *$ & $27190.45 *$ & 29032.41 \\
\hline $\mathbf{L L}$ & & -42330.90 & & & & \\
\hline AIC & & 3.1383 & & & & \\
\hline BIC & & $-262,687$ & & & & \\
\hline Sargan & & & & & $p=0.3778$ & $p=0.5362$ \\
\hline
\end{tabular}

$* \mathrm{p}<.01$; Productivity model uses misfit categories computed from Poisson adoption antecedent model. Heteroscedastic-corrected standard errors used. Adoption models include 20 3-digit industry dummy categories; productivity models include 20 industry and 6 size dummy categories. F-stat is for OLS and Wald-stat is for Poisson regression. SKILL, SIZE, KL, ML, are logarithmic. LL is log likelihood, AIC is Akaike's Information Criterion (smaller value is a better model fit). BIC is Bayesian Information Criterion (more negative model is a better fit). Sargan is a test of overidentifying restrictions: not rejecting the null is consistent with valid instruments.

It is possible that more productive firms are more likely to adopt ENT, which may lead to endogeneity and simultaneity bias. To correct for this possibility, we re-estimated our split sample productivity formulation by instrumenting ENT with other technology variables that do not affect productivity directly (due to low reach and range) yet are correlated with ENT (due to being technology complements): computer aided design and online access to product catalogs. ${ }^{8}$ The last two columns of Table 5 indicate that when

${ }^{8}$ In the business value literature, lagged values are often employed as instruments in two-stage least squares estimation (e.g, Bresnahan et al. 2002). As we do not have time-series data for technology variables, we choose instruments that are a) exogenous and b) correlated with ENT. Lower-level technology variables used in narrow business processes such as computer-aided design (CAD) are likely 
controlling for potential endogeneity, $\mathrm{H} 1$ and $\mathrm{H} 4$ are supported. ENT is positively and significantly associated with labor productivity in both specifications, but firms with a technology misfit have a lower coefficient estimate than do firms without a misfit. The effect is even larger for this improved specification than for OLS, with ENT for no misfit firms being .22 while that of misfit firms being .05 - roughly 4 times larger for fit firms versus misfit firms. We assessed the validity of our choice of instruments by examining first-stage IV estimate results, which reveal a high $F$-statistic and $\mathrm{R}^{2}$ in stage 1 . We also estimated the Sargan statistic, which regresses the residuals from IV stage 1 on included and excluded exogenous variables and tests the hypothesis that all coefficients are jointly zero. Our test statistic ( $p>$.1) supports retention of the null that all are zero. Taken together, first stage IV regression results combined with the Sargan test support our choice of instruments and provide further confidence in our misfit estimation results.

Our baseline results using sample splits are fully supportive of hypotheses H1 and H4. We next estimate models in which dummy variables for misfit are used in productivity estimations. First, we estimate a dummy-variable model using an aggregate misfit category (Table 6, column 1 and 2). As before, we estimate OLS as well as IV, to account for potential endogeneity. Results are strongly supportive of sample split results: the coefficient on ENT is positive and significant while that on the interactive term is negative and significant. This indicates that all things equal, misfit firms $(M F=1)$ have a statistically significant lower coefficient on ENT than do non misfit firms $(M F=0)$. The same pattern of results holds for our instrumental variables specification and the interactive term is increased from -.03 to -.18. Finally, we examine over-adoption and under-adoption misfit (Table 6, columns 3 and 4). Both interactive terms are negative and significant for OLS and IV estimations, while ENT remains positive and significant, in full support of hypotheses H2 and H3. Once again, the misfit effect is larger in magnitude in the preferred IV specification. Finally, we note that for the IV specification the over-adoption misfit effect is slightly larger (.-17) than the under-adoption misfit effect (-.16) (Table 6, column 4).

to be exogenous to our plant-level productivity model, while they are likely to be correlated with ENT. After estimation, standard checks support our choice. 
Table 6: Productivity Estimation - Full Interactive Model

\begin{tabular}{|c|c|c|c|c|}
\hline & \multicolumn{4}{|c|}{ Productivity Model (Interactive Model) } \\
\hline & \multicolumn{2}{|c|}{ Aggregate } & \multicolumn{2}{|c|}{ Misfit Over \& Misfit Under } \\
\hline & OLS & IV & OLS & IV \\
\hline ENT & $\begin{array}{c}.0651 * \\
(.0050)\end{array}$ & $\begin{array}{l}.2352 * \\
(.0430)\end{array}$ & $\begin{array}{l}.0642 * \\
(.0051)\end{array}$ & $\begin{array}{l}.2596 * \\
(.0501)\end{array}$ \\
\hline MF & $\begin{array}{c}.0747^{*} \\
(.0125) \\
\end{array}$ & $\begin{array}{l}.4308 * \\
(.0902) \\
\end{array}$ & & \\
\hline MFO & & & $\begin{array}{l}.0782 * \\
(.0218)\end{array}$ & $\begin{array}{l}.3056 * \\
(.0619)\end{array}$ \\
\hline MFU & & & $\begin{array}{c}.0832 * \\
(.0161)\end{array}$ & $\begin{array}{c}.4445 * \\
(.0936)\end{array}$ \\
\hline MFXENT & $\begin{array}{l}-.0318^{*} \\
(.0050)\end{array}$ & $\begin{array}{c}-.1892 * \\
(.0398)\end{array}$ & & \\
\hline MFOxENT & & & $\begin{array}{c}-.0322 * \\
(.0065)\end{array}$ & $\begin{array}{l}-.1669 * \\
(.0349)\end{array}$ \\
\hline MFUxENT & & & $\begin{array}{l}-.0428 * \\
(.0122)\end{array}$ & $\begin{array}{l}-.1565 * \\
(.0315)\end{array}$ \\
\hline KL & $\begin{array}{l}.0841 * \\
(.0029)\end{array}$ & $\begin{array}{c}.0787 * \\
(.0032)\end{array}$ & $\begin{array}{c}.0841 * \\
(.0029)\end{array}$ & $\begin{array}{c}.0785 * \\
(.0032)\end{array}$ \\
\hline ML & $\begin{array}{c}.5634 * \\
(.0044)\end{array}$ & $\begin{array}{c}.5535 * \\
(.0049)\end{array}$ & $\begin{array}{c}.5634^{*} \\
(.0044)\end{array}$ & $\begin{array}{c}.5522 * \\
(.0050)\end{array}$ \\
\hline Constant & $\begin{array}{c}2.499 \\
(.0389) \\
\end{array}$ & $\begin{array}{c}1.748 \\
(.1126) \\
\end{array}$ & $\begin{array}{c}2.499 \\
(.0389) \\
\end{array}$ & $\begin{array}{c}1.672 \\
(.1344) \\
\end{array}$ \\
\hline $\mathbf{N}$ & 26,992 & 26,992 & 26,992 & 26,992 \\
\hline $\mathbf{R}^{2}$ & .7978 & .7881 & .7978 & .7859 \\
\hline F-stat & $1971.53 *$ & $54536.82 *$ & 1844.34* & 54239.76* \\
\hline Sargan & & $p=0.3329$ & & $p=0.2722$ \\
\hline
\end{tabular}

\subsection{Sensitivity Analysis and Robustness Checks}

We conducted additional analyses to examine whether our results are sensitive to modeling assumptions. First, we used alternative cutoff levels for our misfit computations, including 20 percentile and 1 standard deviation. ${ }^{9}$ Rerunning productivity regression estimations using misfit measures based on these alternative measures resulted in no change in signs or significance in coefficient estimates, which rules out the possibility that our results are sensitive to the particular choice of residual cutoff parameter. Second, we found same signs and significance in stage 1 when using different subsets of adoption predictors in stage 1 (e.g., leaving out size or multi-plant), which helps to rule out the possibility that our results are driven by a particular set of

\footnotetext{
${ }^{9}$ We thank a seminar participant at the University of Michigan for suggesting this analysis.
} 
adoption antecedents. Third, to check the sensitivity of results to the choice of dependent variable in the productivity models we reran all productivity specifications using labor productivity based on value added rather than total value of shipments. This resulted in a similar pattern of results to the pattern of results using shipments. Finally, given that misfit categories differ slightly across the OLS and Poisson specifications, we reran all productivity models using misfit variables generated from our logged (ENT) OLS specification. No change in the overall pattern of results was observed.

\section{Discussion}

Firms adopt information technology innovations for various reasons with various consequences. A large body of prior studies has identified adoption antecedents to help managers make better adoption decisions and to aid technology vendors in their marketing efforts. Likewise, a great deal of prior research in the IT business value stream has identified the organizational performance implications of information technology innovation. Recent studies have urged researchers to examine problems at the intersection of IT adoption and IT business value (Fichman 2004) and to analyze organizational factors that complement IT investment (Brynjolfsson and Hitt 2000; Melville et al. 2004). For example, Bresnahan et al. (2002) find that firm output is higher in firms which employ certain sets of workplace organization strategies (teams, employee involvement groups, etc.) in conjunction with information technology. This and related analyses beg the question of whether firms adopt when they should, and whether there might be performance implications of those whose adoption behavior does not match up with normative expectations.

In this study we identify a knowledge gap at the nexus of IT innovation adoption and IT business value. We develop a new theoretical construct, which we call IT innovation misfit, to refer to those situations in which firms over-adopt or under-adopt relative to the levels implied by their innovation profiles. We refer to a variety of theories (institutional theory, information cascades, managerial fashions) to argue that many factors in addition to those associated with economic rationality drive IT adoption decisions, arguments that are borne out by widespread survey and case evidence of high 
rates of IT innovation adoption failures. Despite overwhelming conceptual and quantitative evidence for the potential existence of IT innovation misfits, we could not identify any prior studies of this phenomenon.

Our novel contribution is not to develop a new modeling technique for identifying adoption antecedents or for measuring the productivity implications of IT investment. Rather, we employed existing models from prior literature and empirically linked them with the concept of IT innovation misfit. We did this by using residuals from an adoption equation to capture misfit, as has been done in prior management literature. The basic notion is that firms that stray far from the linear modeling line are less of a fit to the line than those that stray less, which means that their innovation profile deviates more, and they are a misfit relative to firms that are nearer to the fit line. While not the only way to model the concept of innovation misfit (e.g., we could alternatively ask managers if they perceive that they are a fit for a given technology), theory, prior research, and intuitive considerations support the validity of operationalizing innovation misfit in this way.

Using a standard productivity equation with an interactive term comprising misfit and electronic networking technologies, we found a strong and consistent pattern of negative moderation, i.e., innovation misfit lowers the association between IT innovation and plant productivity. Our results are consistent across a variety of alternative specifications and robustness and sensitivity checks. These results represent an important first step in understanding the mechanisms and consequences of IT innovation misfit.

\subsection{Implications for Research}

Prior studies have variously argued for: (1) a direct link between IT and performance (Brynjolfsson and Hitt 1996), (2) an indirect link operating through mediating variables such as capabilities (Banker et al. 2006), and (3) a contingent link that depends on other variables, such as the presence of complementarities (Zhu 2004). Our study provides new evidence for a contingent link between IT investment and performance. As expected, we show that innovation returns are diminished among firms that exhibit an over- or under-adoption misfit. This suggests that innovation misfit holds promise as an 
important new variable in explaining the complex linkage between IT innovation and performance. In this way, we refine prior findings that IT adoption has a direct correlation with firm-level profit: our results suggest a more complex situation, where the extent to which "more is better" depends on the degree to which a firm fits the profile of a leading innovator.

Our results also shed some additional light on why cumulative adoption so often follows an S-shaped pattern. Traditional innovation theory (Rogers 2003) holds that communication patterns produce this shape. In particular, news of the existence and benefits of an innovation are assumed to take different times to reach different actors (through mass market media and word-of-mouth), with the interplay between these two channels producing the distinctive S-shape. Attewell (1992) posited an alternative explanation that firms sort themselves out based on ability to adopt, and wait until adoption barriers have been sufficiently lowered. Assuming that the ability to adopt in a population of firms falls along a bell-shaped distribution, then if firms do sort themselves out according to ability to adopt, the result would be an S-shaped cumulative adoption curve. For our conceptualization of innovation misfit to be valid, it is imperative for this self-sorting process to occur to some extent, otherwise the adoption prediction vector would not in any way reflect the ability to adopt. The fact that our model behaves as expected lends additional weight to the ability-based explanation for the ubiquitous adoption S-curve.

Finally, our conceptualization of IT innovation misfit might also apply to other types of technological innovations. However, careful analysis of underlying causal mechanisms is required for new contexts to ensure that modeling assumptions are met.

\subsection{Limitations and Future Research}

Our study might be criticized for only applying to a particular type of IT innovation (electronic networking technologies) in a particular context (U.S. manufacturing firms). While this may be true, this is an sizeable sector of the economy (more than $10 \%$ of GDP) and a very important type of IT for this sector. At the same time, future research is 
needed to examine other types of innovations in other contexts to further refine the idea of IT innovation misfit.

Our operational measure of innovation misfit relies on an empirically derived vector of adoption predictors. Our approach intermingles genuine profile deviations with apparent deviations caused by measurement errors (Meilich 2006) and therefore works best when there is a fairly low incidence of errors in measuring profile characteristics. Since our data concern objectively observable quantities and were collected by the US Bureau of the Census we believe that respondents would be especially willing and able to give accurate answers, but this many not be true in other research. Also, our approach assumes that economically rational behavior is prevalent enough to drive the fitted results, but not so prevalent that few misfits remain to actually affect performance (Meilich 2006). We believe that in our situation and many others these assumptions will hold and future research might examine other situations. In some contexts, other approaches might be possible, such as perceptual measures.

Given our use of secondary data, we had to rely on some comparatively generic innovation profile characteristics, rather than characteristics that were closely tailored to the innovations at hand. For example, instead of a rich, context-specific measure of skills and knowledge, we used the ratio of non-production workers to production workers as a proxy measure. Likewise, in lieu of direct measures of managerial professionalism and sophistication, we employed the multi-plant designation as a proxy. In some respects it is useful to be able to show that even fairly generic-and thus more widely available — characteristics result in models that behave as expected. Future research might investigate whether the use of more complete and/or tailored profile characteristics changes the effects of misfit on performance. Still, it important to note that while a less complete adoption prediction model arguably leads to residuals that are a noisier measure of misfit, this would tend to attenuate, rather than exaggerate the estimated impact of misfit on performance (Dewar and Werbel 1979).

Beyond addressing the potential limitations just mentioned, we suggest some additional avenues for future work. First, there is the question of what kinds of firm-level 
conditions lead to innovation fit and misfit? We have posited innovation mindfulness and mindlessness as key antecedents. A number of directions are available to investigate this posited linkage and its implications. We view innovation mindfulness as an important theoretical construct; however, as of yet no measures have been developed for the construct. We suggest that innovation fit/misfit could be positioned as an outcome variable in a nomological network used to evaluate the validity of measures for mindfulness/mindlessness. If the strong expected linkage were found, this would lend more credence to measures of both mindfulness and innovation fit as valid indicators of their underlying theoretical constructs. Also, a direct measure for mindfulness would allow us to sort out the ambiguous effects of under adoption misfit on performance by allowing us to decouple the positive structure effect of being "over qualified" from the negative project execution effect of being less mindful with regard to innovation. Finally, if a strong correlation were found between mindfulness/mindlessness and fit/misfit, then each might be viewed as suitable proxy for the other in future research. Each variable is challenging to capture in practice, but for different reasons: direct measurement of mindfulness/mindlessness requires primary data collection, while fit/misfit requires data sufficient to estimate a sound adoption model. So we can easily foresee circumstances where the theoretical interest is in one construct, but the other is far more feasible to capture.

Another important question concerns the macro-level conditions leading to pervasive misfits in a population of firms. Prior work related to institutional theory, information cascades and managerial fashions has addressed the question of why many firms seem to ignore situational specifics in making managerial decisions. But little of this research has been directed specifically at the domain of IT innovation. We believe our work gives additional motivation to examine these implications of these mechanisms in an IT adoption context.

\subsection{Managerial Implications}

For innovation adopters, our results strengthen the economic rationale for innovating mindfully. While a high innovation fit can be achieved accidentally, or through a 
process of imitating the behaviors of similarly positioned others, we believe the surest route to innovation fit is to engage in a mindful process of ascertaining whether it makes sense for a firm to be a leading adopter based on that firm's individual facts and specifics, and to time adoption accordingly. Certain specifics, such as those examined in our study, apply to a wide variety of innovations, while other perhaps equally important characteristics will depend on the particulars of a given IT innovation. Our results indicate there is a productivity penalty for mindlessly jumping on an innovation bandwagon just because a technology happens to be highly fashionable.

Our results also have implications for innovation proponents and vendors. While these actors have always been interested in the profile of innovation leaders in order to find the most willing adopters, our research suggests that those fitting a normatively-derived leader profile are also more likely to have beneficial innovation outcomes. The implication is that attempting to push the innovation on firms that do not fit the profile can hold dangers going beyond wasted marketing resources: it can increase the incidence of early adopting firms with low economic returns. Such firms might well serve as negative opinion leaders that adversely impact later adoptions.

\section{Conclusion}

An extensive stream of research seeks to identify the profile of IT innovation leaders. Much of this research assumes (whether implicitly or explicitly) a normative stance in which certain firms lead because they are best positioned to derive high innovation returns. We have argued that in the economic ideal, firms would make adoption decisions based on how well they match the normative profile of an innovation leader, and those firms that do will have higher returns to innovation than do firms with misfit between their normative profile and actual adoption behavior. Despite the foundational role that implicit assumptions about innovation fit and misfit have played in prior IT innovation research, no prior work (to our knowledge) has examined these assumptions. Our study fills this gap by theorizing about innovation fit and misfit, developing an approach to operationalizing misfit, and demonstrating that, consistent with expectations, firms with an adoption misfit—i.e., those that are positioned more like 
laggards but behave more like leaders (or vice versa)—see their innovation returns

diminished relative to firms with high innovation fit.

\section{References}

Abrahamson, E. 1996. Management fashion. Academy of Management Review 21(1) 254-285.

Armstrong, C.P., V. Sambamurthy. 1999. Information technology assimilation in firms: The influence of senior leadership and IT infrastructures. Information Systems Research 10(4) 304-327.

Astebro, T. 2002. Noncapital investment costs and the adoption of CAD and CNC in US metalworking industries. RAND Journal of Economics 33(4) 672-688.

Atrostic, B.K. 2007. Measuring U.S. Innovative Activity. U.S. Bureau of the Census, 132.

Atrostic, B.K., S.V. Nguyen. 2005. IT and productivity in U.S. manufacturing: Do computer networks matter? Economic Inquiry 43(3) 493-506.

Attewell, P. 1992. Technology Diffusion and Organizational Learning: The Case of Business Computing. Organization Science 3(1) 1-19.

Avison, D., S. Gregor, D. Wilson. 2006a. Managerial IT Unconsciousness. Communications of The ACM 49(7) 88-93.

Banker, R.D., I.R. Bardhan, C. Hsihui, L. Shu. 2006. Plant information systems, manufacturing capabilities, and plant performance. MIS Quarterly 30(2) 315-337.

Bartelsman, E., M. Doms. 2000. Understanding Productivity: Lessons from Longitudinal Microdata. Journal of Economic Literature. 28(3) 69-594.

Barua, A., P. Konana, A.B. Whinston, F. Yin. 2004. An empirical investigation of Netenabled business value: An exploratory investigation. MIS Quarterly 28(4) 585-620.

Bikhchandani, S., D. Hirshleifer, I. Welch. 1998. Learning from the behavior of others: Conformity, fads, and informational cascades. The Journal of Economic Perspectives 12(3) 151-170.

Black, S.E., L.M. Lynch. 2001. How To Compete: The Impact of Workplace Practices and Information Technology on Productivity. The Review of Economics and Statistics 83(3) 434-445.

Bollingtoft, A., D.D. Hakonsson, J.F. Nielsen, C.C. Snow, J. Ulhoi, eds. 2009. New Approaches to Organization Design. Springer.

Bresnahan, T., E. Brynjolfsson, L. Hitt. 2002. Information Technology, Workplace Organization, and the Demand for Skilled Labor: Firm-level Evidence. Quarterly Journal of Economics.

Brynjolfsson, E., L. Hitt. 1996. Paradox lost? Firm-level evidence on the returns to information systems spending. Management Science 42(4) 541-558.

Brynjolfsson, E., L. Hitt. 2000. Beyond computation: Information technology, organizational transformation and business performance. Journal of Economic Perspectives 14(4) 23-48.

Colombo, M.G., M. Delmastro. 2002. The determinants of organizational change and structural inertia: Technological and organizational factors. Journal of Economics \& Management Strategy 11(4) 595-635. 
Colombo, M.G., R. Mosconi. 1995. Complementarity and Cumulative Learning Effects in the Early Diffusion of Multiple Technologies. Journal of Industrial Economics 43(1) 13-48.

Cooper, R.B., R.W. Zmud. 1990. Information technology implementation research: A technological diffusion approach. Management Science 36(2) 123-139.

Damanpour, F. 1991. Organizational innovation: A meta-analysis of effects of determinants and moderators. Academy of Management Journal 34(3) 555-590.

Dewar, R., J. Werbel. 1979. Universalistic and Contingency Predictions of Employee Satisfaction and Conflict. Administrative Science Quarterly 24(3) 426-448.

DiMaggio, P.J., W.W. Powell. 1983. The iron cage revisited: Institutional isomorphism and collective rationality in organizational fields. American Sociological Review $\mathbf{4 8}$ 147-160.

Doms, M., T. Dunne, K.R. Troske. 1997. Workers, wages, and technology. Quarterly Journal of Economics 112(1) 253-290.

Dunne, T. 1994. Plant-age and technology use in United States manufacturing industries. RAND Journal of Economics 25(3) 488-499.

Dunne, T., L. Foster, J. Haltiwanger, K. Troske. 2000. Wage and productivity dispersion in US manufacturing: The role of computer investment NBER working paper 7465. National Bureau of Economic Research, Cambridge, MA.

Fang, X., S. Chan, J. Brzezinski, S. Xu. 2005. Moderating effects of task type on wireless technology acceptance. Journal of Management Information Systems 22(3) 123-157.

Fichman, R.G. 2000. The diffusion and assimilation of information technology innovations. R.B. Zmud, ed. Framing the Domains of IT Management: Projecting the Future... Through the Past. Pinnaflex Educational Resources, Inc., Cincinnati, $\mathrm{OH}$.

Fichman, R.G. 2004. Going beyond the dominant paradigm for it innovation research: Emerging concepts and methods. Journal of the Association for Information Systems 5(8) 314-355.

Fichman, R.G., C.F. Kemerer. 1997. The assimilation of software process innovations: An organizational learning perspective. Management Science 43(10) 1345-1363.

Gouyette, C., P. Pestieau. 1999. Efficiency of the welfare state. Kyklos 52(4) 537-553.

Hitt, L.M., E. Brynjolfsson. 1996. Productivity, business profitability and consumer surplus: Three different measures of information technology value. MIS Quarterly 20(2) 121-142.

Hitt, L.M., D.J. Wu, X. Zhou. 2002. Investment in enterprise resource planning: Business impact and productivity measures. Journal of Management Information Systems 19(1) 71-98.

Hong, W., K. Zhu. 2006. Migrating to Internet-based E-commerce: Factors Affecting Ecommerce Adoption and Migration at the Firm Level. Information \& Management 43(2) 204-221.

Huigang, L., N. Saraf, H. Qing, X. Yajiong. 2007. Assimilation of enterprise systems: The effect of institutional pressures and the mediating role of top management. MIS Quarterly 31(1) 59-87.

Iacovou, C.L., I. Benbasat, A.S. Dexter. 1995. Electronic data interchange and small organizations: Adoption and impact of technology. MIS Quarterly 19(4) 465-485. 
Ittner, C.D., W.N. Lanen, D.F. Larcker. 2002. The Association Between Activity-based Costing and Manufacturing Performance. Journal of Accounting Research 40(3) 711-726.

Jarmin, R.S., J. Miranda. 2002. The Longitudinal Business Database. U.S.C. Bureau, ed. U.S. Census Bureau, 1-26.

Jayasuriya, R., Q. Wodon. 2003. Efficiency in reaching the millennium development goals. World Bank, http://publications.worldbank.org/ecommerce/catalog/product?item_id=2435559, Washington, DC.

Kakwani, N. 1993. Performance in living standards: An international comparison. Journal of Development Economics 41(2) 307-336.

Long, J.S. 1997. Regression Models for Categorical and Limited Dependent Variables. Sage Publications, Thousand Oaks.

McCullagh, P., J.A. Nelder. 1989. Generalized Linear Models. Chapman and Hall, London.

McElheran, K.S. 2008. Market Leadership and Strategic Investments in Innovation: The Adoption of E-Business Capabilities Academy of Management Best Paper Proceedings, 1-6.

Meilich, O. 2006. Bivariate Models of Fit in Contingency Theory. Organizational Research Methods 9(2) 161-193.

Melville, N., K. Kraemer, V. Gurbaxani. 2004. Review: Information technology and organizational performance: An integrative model of IT business value. MIS Quarterly 28(2) 283-322.

Mishra, A.K., T.A. Park. 2005. An Empirical Analysis of Internet Use by U.S. Famers. Agricultural and Resource Economics Review 34(2) 253-264.

Mukhopadhyay, T., S. Rajiv, K. Srinivasan. 1997. Information technology impact on process output and quality. Management Science 43(12) 1645-1659.

Mustonen-Ollila, E., K. Lyytinen. 2004. How Organizations Adopt Information System Process Innovations: A Longitudinal Analysis. European Journal of Information Systems 13 35-51.

Nelson, R.R. 2007. IT Project Management: Infamous Failures, Classic Mistakes, and Best Practices. MIS Quarterly Executive 6(2) 67-78.

Oliner, S., D. Sichel. 2002. Information Technology and Productivity: Where Are We Now and Where Are We Going? Economic Review 3(3) 15-41.

Power, L. 1998. The Missing Link: Technology, Investment, and Productivity. Review of Economic and Statistics 8(2) 300-313.

Premkumar, G., K. Ramamurthy. 1997. Determinants of EDI adoption in the transportation industry. European Journal of Information Systems 6(2) 107.

Ramamurthy, K., A. Sen, A. Sinha. 2008. An empirical examination of the key determinants of data warehouse adoption. Decision Support Systems 44(4) 817-841.

Rogers, E.M. 2003. Diffusion of Innovations, 5th edition ed. The Free Press, New York.

Sharma, R., P. Yetton. 2003. The contingent effects of management support and task interdependence on successful information systems implementation. MIS Quarterly 27(4) 533-555.

Swanson, E.B. 1994. Information systems innovations among organizations. Management Science 40(9) 1069-1092. 
Swanson, E.B., N. Ramiller. 2004. Innovating mindfully with information technology. MIS Quarterly 28(4) 553-583.

Tornatzky, L.G., M. Fleischer. 1990. The Processes of Technological Innovation. Lexington Books, Lexington, MA.

Zhu, K. 2004. The complementarity of information technology infrastructure and ecommerce capability: A resource-based assessment of their business value. Journal of Management Information Systems 21(1) 167-202.

Zorn, T. 2002. Politics, Emotion, and the Discourse of ICT Adoption and Implementation. University of Waikato, Gold Coast, Australia, 2-16. 